\title{
Haemoglobin disorders-a point of entry for community genetics services in India?
}

\author{
Bernadette Modell ${ }^{1}$
}

Received: 17 May 2019 / Accepted: 3 October 2019 / Published online: 6 December 2019

(C) Springer-Verlag GmbH Germany, part of Springer Nature 2019

It is estimated that when infant mortality is over $40 / 1000$, less than $10 \%$ of the population have access to services for prevention and care of congenital disorders, but nearly $100 \%$ have access when infant mortality is $10 / 1000$ or less (Blencowe et al. 2018a). The difference reflects the demographic transition and shifts the focus of medical policymaking from communicable to non-communicable diseases, including congenital and genetic disorders. This shift now affects the majority of the world population as $73 \%$ of births occur in countries with infant mortality of less than 45 / 1000. The average time taken for infant mortality to fall from 40 to 10 per 1000 births is $30-40$ years (United Nations 2015)—close to the average working life of a health professional.

The question is then arising for an increasing number of countries: What services should be put in place for prevention and care of congenital disorders? The answer differs according to the disorder group. The burden of congenital malformations can be reduced by $80 \%$ by interventions such as folic acid food fortification, early diagnosis, and surgical correction (Czeizel et al. 1993; Moorthie et al. 2018). The birth prevalence of chromosomal disorders can be greatly reduced by antenatal screening with access to prenatal diagnosis and termination of pregnancy (Moorthie et al. 2017). However, possibilities for reducing the burden of single gene disorders are currently much more limited, especially as in most cases there is still no definitive cure. Reproductive risk of early-onset dominant and X-linked disorders can often be identified through family studies, and these are conventional medical genetics practice. By contrast, recessive disorders (which account for around 70\% of early-onset single gene disorders globally) typically present without a family history:

Bernadette Modell

b.modell@ucl.ac.uk

1 WHO Collaborating Centre for Community Genetics, UCL Institute of Health Informatics, 222 Euston Road, London NW1 2DA, UK risk is usually detected only through the diagnosis of an affected child (retrospectively). Counselling the parents on recurrence risk is an integral part of patient care and can be of great benefit for families: however, even avoidance of all recurrences would have little effect on affected birth prevalence in most populations (Blencowe et al. 2018b).

Haemoglobin disorders account for around 15\% of recessive disorders globally. The remaining rare recessive disorders are highly diverse and most are severe: around $80 \%$ cause stillbirth or under-5 deaths and the remainder cause severe long-term disability in the absence of any intervention (Bittles and Black 2010; Blencowe et al. 2018b). Their estimated collective birth prevalence is related to the local prevalence of parental consanguinity and haemoglobin disorders and ranges from around 5/1000 in populations of European origin to $9.8 / 1000$ in India, with a maximum of 26/1000 in Pakistan (Modell et al. 2016). In many cases, the only options are supportive and palliative care. Effective care when feasible can greatly improve survival and quality of life but is usually highly diagnosis-specific and can be very expensive in terms of drugs, biologicals, other medical interventions, and social support. Access to care is estimated to reduce early mortality by around 50\% (Blencowe et al. 2018b), but improved survival leads to a steady, predictable cumulative increase in numbers needing lifelong appropriate care. The resulting dilemma - how to commit to providing optimal care when it may not be affordable in the long term - is an important challenge for high- and lower-income countries. For example, NHS England recently decided against providing lifeprolonging drugs for cystic fibrosis on the ground of unaffordable cost (Walker 2019).

The haemoglobin disorders offer an outstanding exception to this general problem because prospective risk detection through carrier screening has been feasible for many years, is implemented across a wide range of populations and cultures, and can lead to a great reduction in affected birth prevalence. Haemoglobin disorders fall into two main groups. Thalassaemias are in general predictably severe, and carrier 
screening, combined with access to prenatal diagnosis and termination of pregnancy, leads to large reduction in affected births: the same applies for other severe recessive disorders when carriers can be detected prospectively (Mitchell et al. 1996). Thus, in the Mediterranean area, the introduction of carrier screening and genetic counselling enabled a commitment to optimal care for every patient (e.g. Angastiniotis and Hadjiminas (1981)).

Sickle cell disorders are less predictable and are often viewed as less severe than thalassaemia, and demand for prenatal diagnosis is relatively limited in high-income settings (Petrou et al. 1992). However, little information is available on potential demand in the countries where sickle cell disorders are most prevalent. Thus, haemoglobin disorders provide a general model for what may be expected when prospective carrier screening becomes available for a wider range of severe and less severe genetic disorders.

\section{Estimates for India}

India has now reached the point where increasing access to services is predicted to bring about a rapid increase in numbers of patients requiring care. One-third of the population is urbanised, infant mortality is $23 / 1000$ in the urban population and $38 / 1000$ in the larger rural population, and the government recognises the increasing importance of noncommunicable diseases including rare genetic disorders. Since the haemoglobin disorders are the largest group of single gene disorders, 'The Government of India is presently engaged in the implementation of a prevention and control programme for thalassaemia major and sickle cell disease, with guidelines for their prevention and management formulated under the National Health Mission.' (Sinha et al. 2019).

Prenatal diagnosis for thalassaemia is available at a number of Indian centres, and there have been thousands of procedures. However, there has been little impact on affected birth prevalence because less than $6 \%$ are for prospectively detected at-risk couples (PJ Natrajan, personal communication). The new government policy is aimed at maximising prospective risk detection through education and the offer of screening in schools and antenatal carrier screening with access to prenatal diagnosis for the at-risk couples identified.

Policymaking requires a basis in epidemiology and health economics. In support of the government programme, Sujata Sinha and colleagues have taken up the challenge of providing an initial combined assessment - a particularly difficult task considering the enormous size and extreme diversity of the Indian population. Using an average birth prevalence of thalassaemia in India of 0.5/1000, they conclude that if all affected infants were diagnosed and treated in 10 years' time, the annual blood requirement for thalassaemia would equal twothirds of the current total annual blood donations, while total treatment costs would reach nearly $20 \%$ of the current health budget. On the other hand, an effective programme of prospective carrier screening could limit annual blood and treatment costs to less than $10 \%$ of prediction. They also show that bone marrow transplantation is already cost-effective for the $10 \%$ of suitable patients with a compatible donor.

The predominant type of sickle cell disorder in India is considerably less severe than the African type because the associated haplotype enables significant persistent haemoglobin F synthesis: this both raises total haemoglobin level and reduces tendency to sickle. Management is largely protective, is relatively simple, and can be integrated into basic health services, so the initial emphasis is likely to be on neonatal screening. The Indian dilemma therefore applies primarily for thalassaemia.

The authors stress the difficulties involved in making these preliminary estimates because of the size and diversity of the Indian population and the very limited reliable observational data available, both on carrier prevalence and - surprisingly on costs of the different available iron chelating agents. Despite these problems, they convincingly demonstrate that India now faces the same dilemma as earlier in the Mediterranean area - access to care, while reducing mortality, can increase the cost of care beyond the capacity of the health system to provide it. Because of the predicted rapid increase in access to care, they emphasise the need for urgent action. Priorities now are to implement the government policy and ensure effective surveillance, which will in turn generate more reliable epidemiological data.

\section{Wider implications}

The need for genetics services in India is intensified by the fact that the collective birth prevalence of rare recessive disorders is around 9/1000 births (seven times higher than that of haemoglobin disorders) and twice their prevalence in European populations. Thus, the problem presented so starkly by the haemoglobin disorders is only the tip of an iceberg, giving advance warning of a far larger problem. On the other hand, advances in DNA technology, including affordable genome sequencing, now hold out the possibility of prospective carrier detection and counselling for a wide range of rare single gene disorders, as well as hope of a more unitary approach to treatment. India is a large country with advanced technical and scientific resources: the evidence shows the need to prioritise research on prospective carrier detection as part of the national strategy for control of non-communicable diseases. The same applies for high-income countries where it is starting to become clear that even though affected birth prevalence is lower, the development of effective but expensive treatments combined with improving patient survival presents a serious economic challenge for health services. 


\section{References}

Angastiniotis MA, Hadjiminas MG (1981) Prevention of thalassaemia in Cyprus. Lancet 1:369-371

Bittles AH, Black ML (2010) The impact of consanguinity on neonatal and infant health. Early Hum Dev 86:737-741. https://doi.org/10. 1016/j.earlhumdev.2010.08.003

Blencowe H, Moorthie S, Darlison MW, Gibbons S, Modell B, Congenital Disorders Expert G (2018a) Methods to estimate access to care and the effect of interventions on the outcomes of congenital disorders. J Community Genet. https://doi.org/10.1007/s12687-0180359-3

Blencowe $\mathrm{H}$ et al (2018b) Rare single gene disorders: estimating baseline prevalence and outcomes worldwide. J Community Genet. https:// doi.org/10.1007/s12687-018-0376-2

Czeizel A, Intôdy Z, Modell B (1993) What proportion of congenital abnormalities can be prevented? Bmj 306:499-503. https://doi.org/ 10.1136/bmj.306.6876.499

Mitchell JJ, Capua A, Clow C, Scriver CR (1996) Twenty-year outcome analysis of genetic screening programs for Tay-Sachs and betathalassemia disease carriers in high schools. Am J Hum Genet 59: 793-798

Modell B, Darlison MW, Moorthie S, Blencowe H, Petrou M, Lawn J (2016) Epidemiological methods in community genetics and the
Modell Global Database of Congenital Disorders (MGDb). http:// discovery.ucl.ac.uk/1532179/. Accessed 16 July 2019

Moorthie S et al (2017) Chromosomal disorders: estimating baseline birth prevalence and pregnancy outcomes worldwide. J Community Genet. https://doi.org/10.1007/s12687-017-0336-2

Moorthie S et al (2018) Estimating the birth prevalence and pregnancy outcomes of congenital malformations worldwide. J Community Genet. https://doi.org/10.1007/s12687-018-0384-2

Petrou M, Brugiatelli M, Ward RH, Modell B (1992) Factors affecting the uptake of prenatal diagnosis for sickle cell disease. J Med Genet 29: 820-823

Sinha S, Seth T, Colah RB, Bittles AH (2019) Haemoglobinopathies in India: estimates of blood requirements and treatment costs for the decade 2017-2026. J Community Genet. https://doi.org/10.1007/ s12687-019-00410-1

United Nations, Department of Economic and Social Affairs, Population Division (2015). World Population Prospects: The 2015 Revision. http://esa.un.org/unpd/wpp/DVD/. Accessed 17 Dec 2015

Walker C (2019) My son's life depends on this cystic fibrosis drug. And ministers stand in the way. Guardian Newspapers. https://www. theguardian.com/commentisfree/2019/feb/04/save-lives-cysticfibrosis-orkambi-nhs. Accessed 04 Feb 2019

Publisher's note Springer Nature remains neutral with regard to jurisdictional claims in published maps and institutional affiliations. 